\title{
System for laboratory proficiency testing in bacteriology: organisation and impact on microbiology laboratories in health care facilities funded by the Ontario Government
}

\author{
JL WHITBY, WA BLACK, H RICHARDSON, DE WOOD
}

From the LPTP Bacteriology Committee, Ontario Medical Association, 240 St George Street, Toronto, Ontario M5R 2P4, Canada

SUMMARY The Ministry of Health requires that all medical laboratories in the Province of Ontario participate in a laboratory proficiency testing program (LPTP). In bacteriology compliance has been excellent. Eighty-six laboratories, for various reasons over the period under review, have surrendered their licence or, because of poor performance on LPTP test surveys, have had their licence withdrawn by the Ministry. The highest percentage of withdrawals occurred in small hospitals in isolated areas. In April 1979 there were 249 participating laboratories.

Participants' results are first analysed by computer, and, subsequently, approximately $20 \%$ of participants' reports are reviewed by the Committee. Various Committee actions ensue: correspondence with the laboratory director regarding errors; an offer of a visit; and possibly a report via a senior LPTP committee to the Ministry that a laboratory is non-proficient and, in LPTP's terms of reference, non-remediable. Subsequent Ministry action might be the withdrawal of a $\frac{\circ}{D}$ laboratory's licence. However, this last recourse only occurs when educational efforts have proved ineffectual.

Overall, performance in LPTP bacteriology surveys has improved over the period 1975-8, with $68 \%$ of 263 laboratories achieving a score of $70 \%$ or higher and $26 \%$ of 263 laboratories scoring less than $60 \%$.

The Province of Ontario requires that all laboratories engaging in the practice of bacteriology submit to proficiency testing. Proficiency testing in laboratory medicine (including bacteriology) is carried out by the Laboratory Proficiency Testing Program (LPTP), which is under the auspices of the Ontario Medical, Association (OMA). The Program was established by the OMA in response to a request by the government of the Province and superseded a voluntary program operated by the OMA.

LPTP is staffed by a salaried laboratory physician who directs the Program. He is assisted by a systems engineer, consultant technologists, computer programmers, educational officers and administrative staff. The professional aspects of the proficiency testing program, for each of the laboratory disciplines, are handled by committees composed

Accepted for publication 10 June 1981 primarily of laboratory physicians with a special interest in the field. These working committees 0 oversee the testing procedures and the assessment of $₹$ the participants' performance. Laboratories identi-음 fied by the working committees as "non-proficient" $>$ are further reviewed by LPTP's senior committee, the Steering Committee, which comprises a chairman, $N$ the chairmen of each of the eight working committees. and representatives of the Section on Laboratory 0 Medicine of the OMA and the Ontario Hospital N Association. After review by the Steering Com-O mittee, information concerning laboratories ratedo non-proficient and, in LPTP's terms of reference, non-remediable, is referred to the Conjoint Com- $\stackrel{\oplus}{\rightarrow}$ mittee for its action. The Conjoint Committee ist composed of representatives of the Ontario Ministryo of Health and the OMA and is the interface between the Ministry and the Program.

This paper outlines the administrative and 
evaluation procedures of the Bacteriology Committee of LPTP soon after it was formed, and assesses the impact of the Program on the practice of bacteriology in the Province of Ontario. It is not concerned with providing detailed information of deficient performance or analysing possible reasons for poor performance.

\section{Material and methods}

\section{TESTING SCHEDULE}

Each participating laboratory receives six sets of testing material per year: four sample vials, containing one or more lyophilised organisms, make up a set. Each set constitutes one survey. Table 1 lists the organisms distributed by LPTP for the period 1975-9. The participating laboratories are required to isolate, characterise and identify the organisms, as well as to perform appropriate antibiotic susceptibility testing. A written report, on the analysis worksheet provided for each vial of material tested, is to be returned to LPTP within two weeks of receipt of the specimen.

\section{SPECIMEN PREPARATION AND DISTRIBUTION} The lyophilised microbial cultures used for testing are prepared under the direction of two Committee members at their academic institution. Appropriate bacterial cultures are selected and lyophilised in $2 \mathrm{ml}$ vials using a Virtis model 25-SRC-3 cabinet freeze dryer. The suspending medium used is: nutrient

Table 1 Organisms submitted for proficiency testing 1975 to 1979

\begin{tabular}{|c|c|c|c|}
\hline Gram-negative & Frequency & Gram-positive & Frequency \\
\hline Escherichia coli & 4 & Staphylococcus aureus & 4 \\
\hline Proteus sp & 6 & Staphylococcus & \\
\hline Providencia sp & 2 & epidermidis & 2 \\
\hline Enterobacter sp & 3 & Lancefield group A & \\
\hline Klebsiella sp & 7 & streptococci & 1 \\
\hline Serratia sp & 4 & Lancefield group B & \\
\hline Edwardsiella tarda & 3 & streptococci & 1 \\
\hline Yersinia sp & 3 & Streptococci (others) & 3 \\
\hline Shigellae & 7 & Streptococcus & \\
\hline Arizonae & 3 & pneumoniae & 5 \\
\hline Citrobacter sp & 4 & Bacillus cereus & 1 \\
\hline Salmonella sp & 5 & Clostridium & \\
\hline Flavobacterium sp & 2 & perfringens & 2 \\
\hline Pasteurella multocida & 2 & Clostridium septicum & 1 \\
\hline Acinetobacter sp & 1 & Corynebacterium & 1 \\
\hline Pseudomonas & & diphtheriae & 3 \\
\hline aeruginosa & 7 & Corynebacterium & \\
\hline Pseudomonads & 3 & ulcerans & 1 \\
\hline Haemophilus influenzae & 5 & Listeria & \\
\hline Bordetella & & monocytogenes & 2 \\
\hline parapertussis & 1 & Nocardia asteroides & 1 \\
\hline Neisseria gonorrhoeue & 6 & Candida albicans & 1 \\
\hline Neisseria meningitidis & 3 & & \\
\hline Neisseriae (others) & 5 & & \\
\hline Moraxella sp & 2 & & \\
\hline Bacteroides fragilis & 1 & & \\
\hline
\end{tabular}

broth (Difco 0003-01) 0.4 g; glucose $15.0 \mathrm{~g}$; distilled water $50 \mathrm{ml}$. The suspending medium is then sterilised at $121^{\circ} \mathrm{C}$ for $20 \mathrm{~min}$ and $150 \mathrm{ml}$ of Seitzfiltered horse serum is added. The biochemical characteristics and antibiotic susceptibility patterns of the selected organisms are confirmed by several Committee members. Vials (packs of four) are packed in custom-made, expanded-polyethylene foam containers. A unique identification label is fixed to each sample vial-for example, B-82-1 (bacteriology, February 1979 survey, sample vial number 1 ). The packages are distributed to participants by registered mail. On receipt, the lyophilised vials are to be reconstituted in accordance with previously issued instructions. The clinical history provided for each sample-for example, swab from a decubitus ulcer, serves to suggest appropriate media for the inoculation of the sample and perhaps suggests which antibiotics might be tested.

\section{PARTICIPANTS' REPORTING PROCEDURE}

In order to set up a computer-compatible system, a coding system was prepared for all bacteria which were likely to be used in the proficiency testing program. This system, known as the Ontario System for Identification of Medically Important Bacteria (OSIMIB), is described elsewhere. ${ }^{1}$

An analysis worksheet was also prepared for recording of results by the participant. The laboratory director receives an analysis worksheet in duplicate. The worksheet allows the laboratories' findings to be recorded in a uniform way thus facilitating data retrieval. Data are entered on the analysis worksheet in the following manner: the five digit OSIMIB code is used for the identification of the organism; susceptibilities are entered as sensitive (S), resistant (R), or intermediate (I); and, biochemical results are entered as positive $(+)$, negative $(-)$ or no reaction $(\mathrm{N})$. There is space on the back of the analysis worksheet for details of Gram stain findings and descriptions of morphology of the organism and its cultural requirements. Serological or other test results may be entered, as well as additional antibiotic, and biochemical test results. The information on the back is not entered into the computer file but is available, if necessary, to assist in evaluating the performance of laboratories that require review. After completion, one copy of the analysis worksheet is returned to LPTP and the other (the working copy) is retained by the laboratory as a record of their submitted results.

Data from each analysis worksheet are entered on a floppy disc which is then transmitted via telephone line to a remote computer, IBM 3033. The programs for data analysis and retrieval are written in PL/I. 


\section{LABORATORY PERFORMANCE REVIEW}

The initial evaluation of the participants' performance is based on a scoring system which allows review of performance by computer analysis. The scoring system is arbitrary, but it does facilitate a rapid screening evaluation of the performance of all participants.

Marks are assigned to three separate aspects of the report:

1 The correct identification of the submitted culture (which is that considered by the Com-

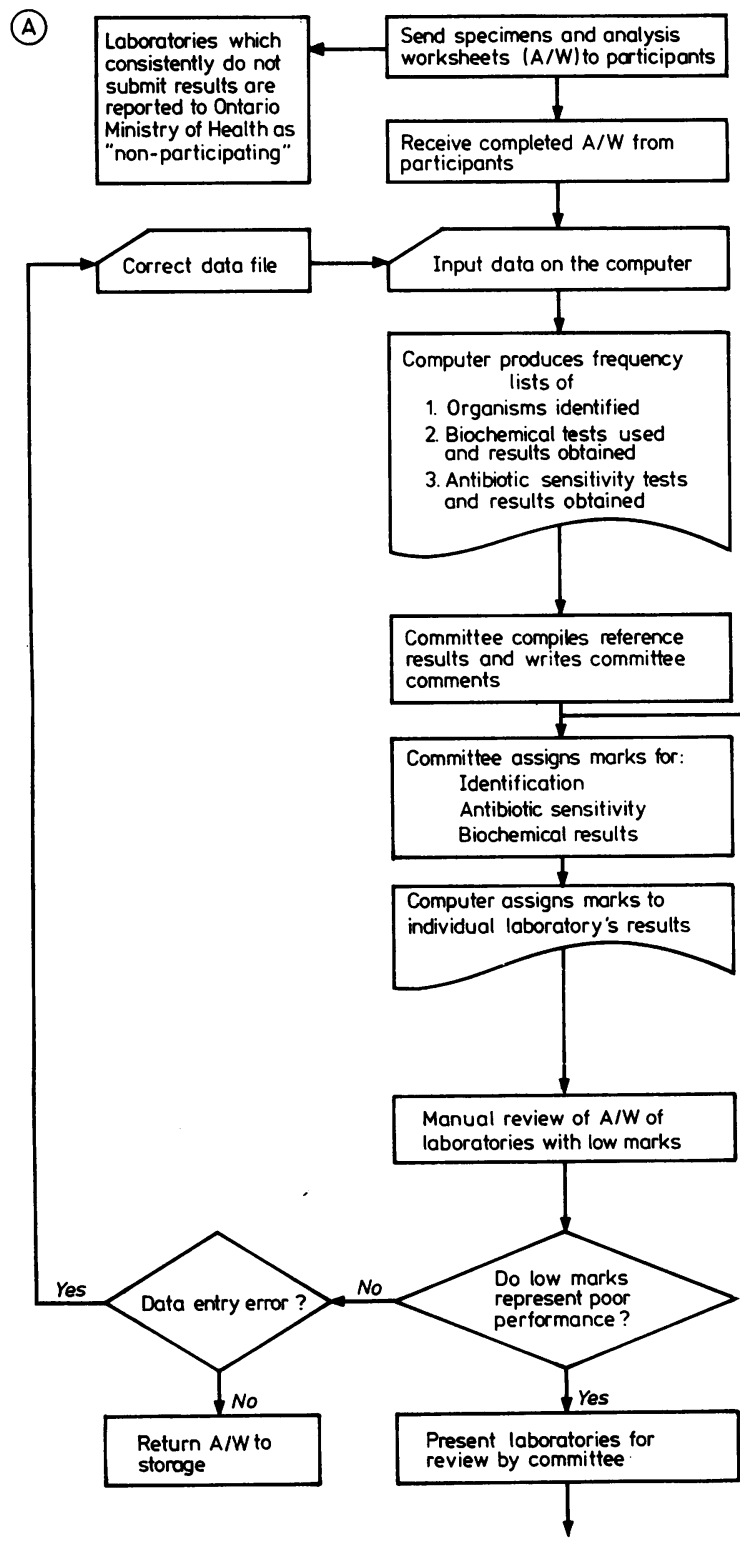

mittee to be the least specific identification compatible with safe and effective patient management) is awarded three marks. One or two marks may be awarded for other identifications which, in some degree, the Committee considers acceptable.

2 Up to six marks are awarded for antibiotic susceptibility tests. The tests scored are the six most frequently reported by participants.

3 Up to eight marks are awarded for biochemical tests. Tests are awarded marks according to how "appropriate" they may be in helping to reach the correct identification of the organism.

The decision-making flow diagrams followed on each bacteriology survey are shown as Figs. 1A and 1B. As shown in Fig. 1B, the options open to the Committee include: closing the file; continuing to monitor; writing to the laboratory director drawing attention to the laboratory's poor performance and requesting an explanation; or, offering a visit by program consultants. If, after a visit, the poor performance of a laboratory continues, the laboratory's record is then referred to the Steering Committee.

Some further explanation of the Committee $\vec{\bullet}$ review is required. The initial screening of laboratory performance is effected through the computer program which identifies every laboratory that has an average score per sample vial of less than eight over the previous six surveys; it also identifies every laboratory that has scored less than $50 \%$ on the

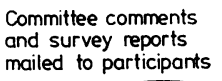

Fig. 1A Flow diagram for review decisions

current survey. The files which LPTP maintains on each laboratory are then reviewed by the LPTP 0 technological consultant and a Committee member? and they decide which of the laboratories require? review by the full Committee. This initial review takes about three hours per survey, depending on the $\mathscr{N}$ number of files. At the full Committee meeting, the $N$ Committee member, acting as reviewer, presents a report on the laboratories with poor performance. $\sigma$ Such laboratories receive careful review by the Committee.

The computer analysis of the survey results is the main component of the survey report* which is sent to all participants. The survey report lists: (i) the

* Readers may obtain examples of the analysis worksheeț and survey report by writing to DEW (address as for reprintD requests). 


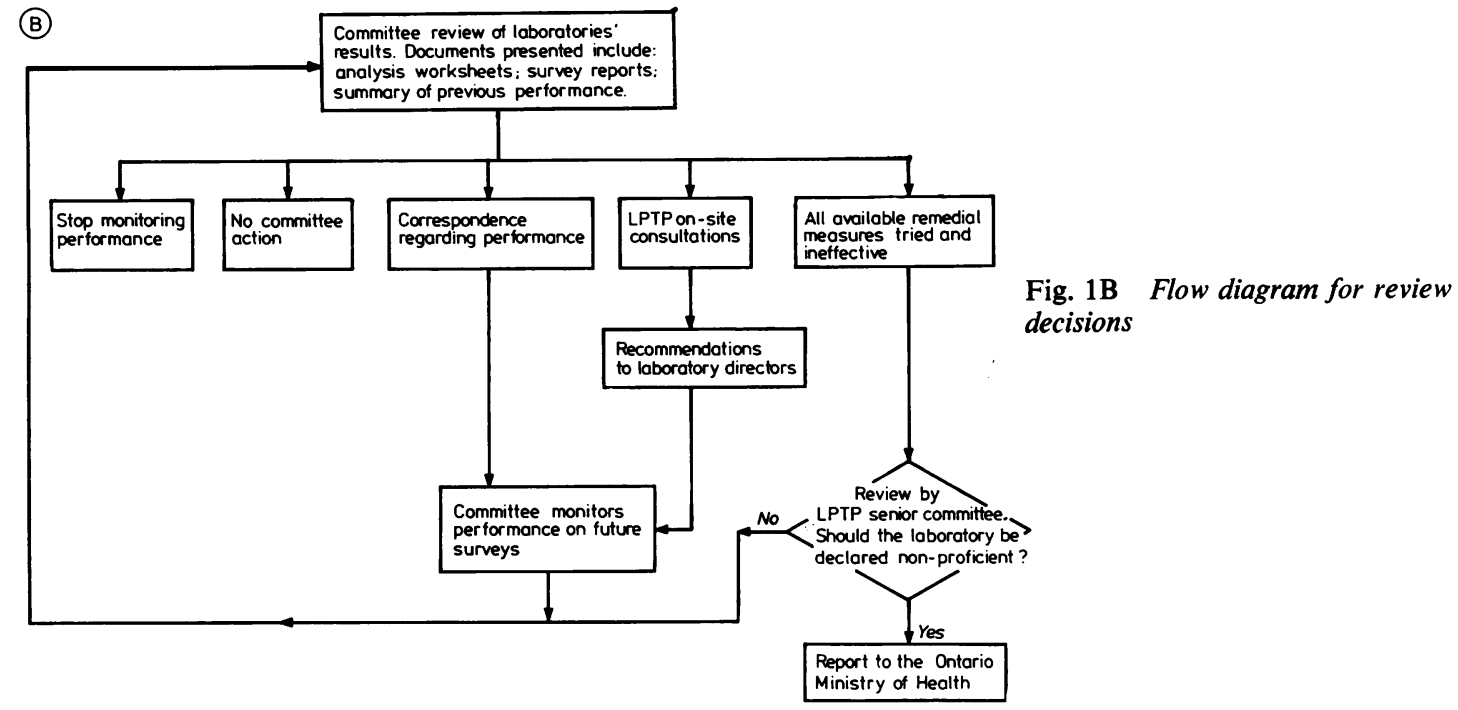

biochemical and antimicrobial susceptibility results reported by the specific laboratory; (ii) the reference results; (iii) the findings of all other participants and the total number of participants performing each test. The reference organism(s) and the organism(s) isolated by individual laboratories are shown. All participants are provided with "feedback" in the form of written Committee comments on each organism submitted for testing. The Committee comments are a critique on the main distinguishing characteristics of the organism, with emphasis on problem areas encountered by the participants. Specific recommendations are made on the performance and interpretation of appropriate tests. Comments are included, where appropriate, on the clinical significance of the organism. Also included in the Committee comments are the number of laboratories submitting results on a particular sample vial, the organism identifications made by these laboratories, and the frequency of identification.

\section{Results}

Change in laboratory performance has been examined for the years 1975 and 1978 using the computergenerated score derived as described above. Seven surveys were undertaken in 1975, with an average total score of 51 . Six surveys were conducted during 1978 , with an average total score of 54 . The scores for all participants are shown in Fig. 2, expressed as the number of laboratories attaining a given percentage of the average total score. In $1975,58 \%$ of 284 laboratories achieved a score of $70 \%$ or higher, whilst in $1978,68 \%$ of 263 laboratories reached this

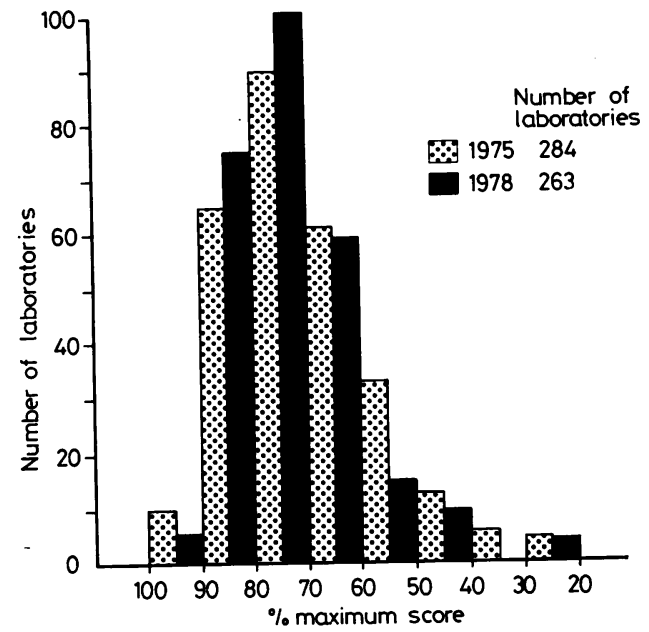

Fig. 2 Laboratory scores for 1975 and 1978

standard. Further, in 1975, of 284 laboratories, 55 scored less than $60 \%$, whilst in 1978 this number was 26 of 263.

Between January 1975 and April 1979, the number of laboratories participating in the program at any one time fell from 319 to 249 , a drop of $22 \%$. The actual number of licensed laboratories voluntarily withdrawing from the program was 86 because 19 laboratories were added to the testing program in the same four years. Three laboratories were removed from the program to a special status, "licensed but not tested," because they performed only Gram stains before referring the specimen to another laboratory. Tables 2,3 and 4 give further 
Table 2 Geographical location and category of the microbiology laboratories withdrawing from proficiency testing

\begin{tabular}{|c|c|c|c|}
\hline \multicolumn{2}{|l|}{ Location } & \multicolumn{2}{|c|}{ Type of laboratory } \\
\hline \multicolumn{2}{|c|}{ Metropolitan Toronto } & \multirow{2}{*}{\multicolumn{2}{|c|}{$\begin{array}{l}\text { Hospital } \\
\text { Private } \\
\text { Hospital } \\
\text { Private }\end{array}$}} \\
\hline \multicolumn{2}{|c|}{ Southwestern Ontario } & & \\
\hline \multicolumn{2}{|l|}{ Central Ontario } & \multicolumn{2}{|l|}{$\begin{array}{l}\text { Hospital } \\
\text { Private }\end{array}$} \\
\hline \multicolumn{2}{|l|}{ Eastern Ontario } & \multicolumn{2}{|l|}{$\begin{array}{l}\text { Hospital } \\
\text { Private }\end{array}$} \\
\hline \multicolumn{2}{|c|}{ Northwestern Ontario } & \multicolumn{2}{|l|}{$\begin{array}{l}\text { Hospital } \\
\text { Private }\end{array}$} \\
\hline \multicolumn{2}{|c|}{ North Central Ontario } & \multicolumn{2}{|c|}{$\begin{array}{l}\text { Hospital } \\
\text { Private } \\
\text { Public Health Laboratories }\end{array}$} \\
\hline \multicolumn{4}{|c|}{$\begin{array}{l}\text { Table } 3 \text { Hospital laboratories withdrawing from } \\
\text { proficiency testing related to hospital size }\end{array}$} \\
\hline No of hospital beds & Total tested & $\begin{array}{l}\text { No } \\
\text { withdrawing } \\
\text { (closed) }\end{array}$ & $\begin{array}{l}\% \\
\text { withdrawing } \\
\text { (closed) }\end{array}$ \\
\hline 50 & 17 & 9 & 52 \\
\hline $51-125$ & 52 & 7 & 13 \\
\hline $126-250$ & 42 & 6 & 14 \\
\hline $251-500$ & 45 & 0 & 0 \\
\hline$>500$ & 22 & 0 & 0 \\
\hline All hospitals & 178 & 22 & 12 \\
\hline
\end{tabular}

Table 4 Reasons for laboratories surrendering their licence in bacteriology

\begin{tabular}{|c|c|c|c|c|}
\hline & \multirow[t]{2}{*}{ No } & \multicolumn{3}{|l|}{ Category } \\
\hline & & Hospital & Private & Government \\
\hline \multicolumn{5}{|l|}{ Never participated in } \\
\hline Regionalisation* & $\begin{array}{l}43 \\
11\end{array}$ & $\begin{array}{r}10 \\
2\end{array}$ & $\begin{array}{r}31 \\
6\end{array}$ & $\begin{array}{l}2 \\
3\end{array}$ \\
\hline \multicolumn{5}{|l|}{ Poor performance' } \\
\hline - bacteriology & 28 & 10 & 17 & 1 \\
\hline - other classes of tests & 4 & & 4 & \\
\hline Total & 86 & 22 & 58 & 6 \\
\hline
\end{tabular}

* Three additional laboratories closed because of regionalisation. Their performance was poor while they were participating and. therefore, have been included under "Poor performance".

$\uparrow$ Four laboratories had satisfactory bacteriology performance, but had significant difficulties with LPTP testing in other classes of tests which necessitated the whole laboratory licence being surrendered.

information about the laboratories which withdrew. It is clear that most of the withdrawals were private laboratories, though the highest percentage of withdrawals occurred in small hospitals (a large number located in North Western Ontario). The four Public Health laboratories were closed due to government economy measures, not because of poor performance.

Laboratories surrendered their licence in bacter $\stackrel{\circ}{+}$ ology for three reasons:

(i) Non-participation (43).

(ii) Regionalisation.

(iii) Poor performance, either in bacteriology $\left(28 \frac{9}{2}\right.$ or in other LPTP classes of tests (4).

Compliance with reporting requirements has beeq9 excellent: $97 \cdot 1 \%$ of all laboratories receiving test samples returned their results on time. Betweem $0.4 \%$ and $4.5 \%$ of participating laboratories we non-reporting in any single survey, and the two-ye average of non-reporting was $2 \cdot 1 \%$. Excluding or survey where the return of results was hindered bo a postal strike, between $0 \%$ and $1.9 \%$ of pa $\overrightarrow{\vec{E}}$ ticipating laboratories were late in submitting the results in a single survey and the two-year averag was $0.5 \%$ of all participants. In general terms, the Committee did not view non-compliance as evidenee of non-proficiency. It was the Committee's view that non-compliance was possible for a variety of reason many of which were fully justified. On the otherp hand, as LPTP is a mandatory program, repeatec non-compliance was viewed as a failure to comply with the Public Health Act of the Province of Ontario. The Ministry of Health of the Provin was notified of such non-compliance and sub: sequently took appropriate disciplinary steps.

Table 5 summarises the number of laboratories reviewed at the various steps in the flow diagrans (Figs $1 \mathrm{~A}$ and 1B). Any one laboratory may be reviewed for one or more reasons. Usually, the tota number of laboratories reviewed is less than $20 \%$ the number of participating laboratories.

\section{Discussion}

A unique balance of responsibility has been created in Ontario with regard to proficiency testing laboratory performance in bacteriology. LPTP $\underset{\text { is }}{\text { is }}$ 
Table 5 Committee review of low scoring bacteriology laboratories in 1978 and effect on licence status

\begin{tabular}{|c|c|c|c|c|c|c|c|c|}
\hline \multirow{2}{*}{$\begin{array}{l}\text { Survey } \\
\text { number }\end{array}$} & \multirow{2}{*}{$\begin{array}{l}\text { No of } \\
\text { laboratories } \\
\text { tested }\end{array}$} & \multicolumn{4}{|c|}{ No of laboratories reviewed } & \multicolumn{3}{|c|}{ Outcome of review } \\
\hline & & $\begin{array}{l}\text { With low } \\
\text { average } \\
\text { score }\end{array}$ & $\begin{array}{l}\text { With a score } \\
\text { of } 50 \% \text { on } \\
\text { survey }\end{array}$ & $\begin{array}{l}\text { Continue to } \\
\text { monitor from } \\
\text { previous } \\
\text { survey }\end{array}$ & $\begin{array}{l}\text { Total } \\
\text { reviewed }\end{array}$ & $\begin{array}{l}\text { Letter of } \\
\text { concern } \\
\text { sent }\end{array}$ & $\begin{array}{l}\text { Visit } \\
\text { recommended }\end{array}$ & $\begin{array}{l}\text { Referred to } \\
\text { Steering } \\
\text { Committee }\end{array}$ \\
\hline B-62 & 262 & 45 & 1 & 36 & 57 & 3 & 2 & - \\
\hline B-64 & 259 & 24 & 1 & 38 & 43 & 3 & 1 & - \\
\hline B-66 & 259 & 38 & 6 & 28 & 47 & 2 & 1 & - \\
\hline B-68 & 257 & 19 & 26 & 31 & 42 & 7 & 2 & - \\
\hline B-70 & 256 & 14 & 1 & 24 & 28 & 5 & 0 & - \\
\hline B-72 & 254 & 16 & 63 & 16 & 73 & 4 & 0 & - \\
\hline
\end{tabular}

identified under the legislation of the Province of Ontario. ${ }^{2}$ This allows direct reporting to the Ministry of Health. The reports to the Ministry of Health from LPTP fall within four areas:

(i) Financial statements accompanied by appropriate auditing.

(ii) Reports on the Program's own performance.

(iii) Reports on non-participating laboratories.

(iv) Reports on non-proficient and nonremediable laboratories.

A clear separation does, however, exist between the Program and the Ministry of Health. The day-today operation of the Program rests with a professional association-namely, the OMA, and the Program, while being mandatory, maintains a significant educational profile. This "separation" means that although information from LPTP concerning an individual survey may be shared with the laboratory director and, where appropriate the laboratory owner, it would not, under normal circumstances, reach the Ministry of Health (Fig. 1B).

The affiliation of proficiency testing with a licensing body has been considered a disadvantage ${ }^{3}$ in that the affiliation may destroy educational aspects of the Program, and that professional bodies should be involved in communicating with and helping poorly performing laboratories. The latter bodies may well be the most acceptable route, but whatever method is used, it does seem that there will be circumstances where the withdrawal of a licence is appropriate.

Because laboratories show better performance when they are handling proficiency testing samples as opposed to "patient material", 45 the use of blind samples is preferred. Such samples are not suitable for a large program such as ours (although they may be a useful aid to an inspection or consultation visit). ${ }^{6}$ Our test samples are clearly labelled and identified as proficiency testing material. The level of performance on test samples may be higher than that obtained on routine patient specimens. This probably means that the results reported represent a lab- oratory's best effort. Nevertheless, a proficiency testing program is a valid means to identify poor performance and furthermore, trends in proficiency testing results may reflect trends in clinical practice.

We are interested in the reasons for laboratories withdrawing from the program. Some laboratories probably never practised bacteriology but viewed the acquisition of a licence as a potential area of growth. Ministry of Health fees may rise sufficiently so that smaller laboratories could not justify continuing. ${ }^{7}$ (The current LPTP fees are Cdn $\$ 465 / y r$.) Other laboratories surrendered their licence because the LPTP results indicated to the laboratory director that the laboratory was performing poorly. We believe that many laboratories, on reviewing their LPTP results, recognised their shortcomings and upgraded their performance.

Where laboratories surrender their licence, or where the licence is withdrawn by the Ministry of Health based on LPTP data, the community may be deprived of its bacteriology service. The Ministry of Health, the OMA and LPTP are aware of this possibility. With private laboratories, up to now, it would seem that alternatives can usually be found and a licence can be surrendered or withdrawn without leaving a community bereft of service. The situation with hospitals is different. In remote areas, bacteriology services might, through necessity, be provided by one small hospital laboratory, where one or two employees may work in all "classes of tests." If they lack training, skill and motivation, and access to continuing educational opportunities, it is probably futile to look for any notable improvement. LPTP results highlight the fact that Ontario, along with other jurisdictions, has regions where the population density is low and it is difficult to maintain acceptable standards of laboratory practice. A special program, the Educational Assistance Program (EAP), has been developed to tackle this problem. ${ }^{8}$

It has been suggested that participants in a proficiency testing program should foster a more rational approach to the handling of clinical speci- 
mens. ${ }^{9}$ We have established "Minimal Requirements for the Laboratory Practice of Medical Microbiology-Bacteriology" 10 which reflect the standard of practice expected of clinical laboratories.

Our program emphasises the educational and self-improvement aspects of proficiency testing. The complete profile on biochemical characteristics and the antibiotic sensitivity of each organism submitted for testing which is returned to participants provides a valuable and accessible reference. ${ }^{11}$ It also allows each laboratory to build-up a collection of stock standard controls as recommended in the Laboratory Regulation Manual. ${ }^{12}$ Throughout the program the emphasis is on problem identification and continuing education. General comments on errors made by laboratories are prepared by the Committee members and distributed to all participating laboratories. In addition, broadsheets on specific microbiological procedures are written and visits are offered to consistently poor performers. It is only as a last resort that recourse is made to the licensing (regulatory) arm of the Ministry of Health concerning a few consistently poor-performing laboratories.

In measurable performance on proficiency testing samples submitted by this program, we have demonstrated improved performance during the period 1975 and 1978. Comparison of our program with other testing programs ${ }^{313}$ is difficult because of the diverse methodologies.

The authors would like to thank the LPTP Bacteriology Committee members for the years 1975 to 1979 , inclusive, for their valuable assistance. Of the several LPTP staff members who assisted, the authors would particularly like to thank Mr Shaul Ezer, Systems Engineer.

\section{References}

1 Black WA. A practical system of bacterial nomenclature. $J$ Clin Pathol 1975;28:746-9.

2 The Health Disciplines Act. 1974. part III. Medicin' section 46.(2) (c): 29.

"Stokes EJ. Whitby JL. Quality control in bacteriology preliminary trials. J Clin Patho/ 1971:24:790-7.

Black WA, Dorse SE. Whitby JL. A regional quality control program in microbiology. I. Administrative aspects. Am J Clin Pathol 1976:66:401-6.

:Black WA, Dorse SE. A regional quality control program in microbiology. II. Advantages of simulated clinical specimens. Am J Clin Pathol 1976:66:407-15.

"Prier JE. The role of the State Public Health Laboratory in external quality control. Baltimore: University Park Press, 1975:137-44

' LaMotte LC Jr. The impact of laboratory improvement programs on laboratory performance: the CLIA 67 experience. Hialth Lab Sci 1977;14:213-23.

* Woodcock SM. Educational Assistance Program. Ontario Medical Technologist, Ontario Society of Medical 음 Technologists 1980; vol 1. No 2:12-3.

"Bartlett RC. Can we afford the price of quality? In: Prier JE. Bartola J. Friedman H. Quality control in microhiolog. Baltimore: University Park Press. 1975:1-9.

1" Bacteriology Committee of LPTP. Minimal requirements for the laboratory practice of medical microbiologybacteriology. LPTP Bacteriology Binder, section 4. March 20 1979:13-4.

1 Porres JM. Quality control in microbiology. I. Utilisation? of reference laboratory data. Am J Clin Pathol 1974: $62: 407-11$.

12 Laboratory Regulation Manual. Federal Quality Control Requirements 2-2. Quality Control of Specific Departments. 2-2A Microbiology 33:13-4.

${ }_{13}$ Schaeffer M, Widelock D, May PS, Blatt S, Wilson ME. \& The clinical laboratory improvement program in New York City. II. Progress after five years of experience. Health Lah Sci 1970:7:242-55.

Requests for reprints to: Dr DE Wood, Director, LPTP응 Ontario Medical Association, 240 St George Street, Toronto, Ontario M5R 2P4, Canada 